\title{
Afinando reflexões sobre um mundo em colapso
}

Filosofia, Letras e Ciências Humanas,

Departamento de Antropologia, São

Paulo, SP, Brasil, hbuarque@usp.br

https: / / orcid.org/0000-0001-8126-5884

Renato Sztutman

Universidade de São Paulo, Faculdade de

Filosofia, Letras e Ciências Humanas,

Departamento de Antropologia, São

Paulo, SP, Brasil, rsztutman@usp.br

https://orcid.org/0000-0003-3871-4984

Pedro de Niemeyer Cesarino

Universidade de São Paulo, Faculdade de

Filosofia, Letras e Ciências Humanas,

Departamento de Antropologia, São

Paulo, SP, Brasil, pncesarino@usp.br

https://orcid.org/0000-0002-4158-7712

Laura Moutinho

Universidade de São Paulo, Faculdade de

Filosofia, Letras e Ciências Humanas,

Departamento de Antropologia, São

Paulo, SP, Brasil, Imoutinho@usp.br

https: //orcid.org/0000-0001-6479-2711

Júlio Assis Simões

Universidade de São Paulo, Faculdade de

Filosofia, Letras e Ciências Humanas,

Departamento de Antropologia, São

Paulo, SP, Brasil, juliosimoes@usp.br

https://orcid.org/0000-0002-9000-3621 
Neste volume da revista, artigos sobre temas e perspectivas diversas da antropologia retomam questões que continuam na ordem do dia de nossa disciplina, e destacam-se temáticas candentes no mundo contemporâneo que têm mobilizado ações políticas ou outras formas de resistência no cotidiano de grupos subalternizados. Situações de violência ou risco que permeiam as páginas dos jornais são compreendidas do ponto de vista de quem sofre e resiste à violência, inclusive aquela cometida pelo Estado através da polícia ou de seus planos de desenvolvimento e ocupação de territórios. De certa forma, vê-se aqui uma antropologia engajada em compreender uma ampla diversidade de acontecimentos em pauta no mundo contemporâneo e, como é recorrente em nossa disciplina, desnaturalizando explicações fáceis e mostrando modos outros de compreender e lidar com fatos históricos, memórias, guerras e mortes violentas. Diante deste quadro, não surpreende que, em vários artigos, os mortos, antepassados ou espíritos sejam tão presentes na experiência de nossos interlocutores de pesquisa.

Alguns artigos refletem sobre circunstâncias sociais de extrema violência e desigualdade que têm marcado a experiência contemporânea, aprofundando abordagens sobre a relação do Estado com grupos em situação de vulnerabilidade. Outro tema recorrente são os efeitos e usos da memória na produção de rituais e na ação cotidiana rituais e ações que muitas vezes surgem como formas de resistência a agressões de longa duração, ou modos de subsistir em contexto de profunda desigualdade social.

A relação entre a antropologia e as páginas dos jornais fica evidente com o primeiro artigo deste volume. No mês em que preparávamos esta edição da Revista de Antropologia, mais uma chacina foi noticiada: em 6 de maio de 2021, uma operação da Polícia Civil do Rio de Janeiro na comunidade do Jacarezinho, zona norte, deixou 29 mortos. O primeiro morto teria sido um policial, e a matança posterior, segundo relatos, parece ter resultado da busca por vingá-lo. Diversas versões tentam justificar a operação, considerando a decisão do Supremo Tribunal Federal de restringir a realização de ações policiais deste tipo durante a pandemia de Covid-19, a não ser em "hipóteses absolutamente excepcionais" - no que consiste essa excepcionalidade é certamente um dos dilemas em jogo.

No artigo que abre este volume, "Viver sem guerra? Poderes locais e enfrentamentos de gênero no cotidiano popular", de Patrícia Birman e Camila Pierobon, a rotinização de uma sequência de casos deste tipo é associada a uma "guerra sem fim". Há cerca de 40 anos esse modo de operação revela a faceta mais cruel do Estado 
brasileiro, com mortes causadas por suposto "confronto". Se nas mídias e telejornais o que prevalece são os conflitos entre homens (policiais e traficantes), mobilizando códigos de masculinidade calcados na brutalidade e na violência extrema, Birman e Pierobon destacam atuações femininas, na costura de relações de gênero, família e vizinhança. $O$ artigo reconstitui as agências femininas em territórios em disputa entre Estado e tráfico, acompanhando o trabalho da memória na situação de três mulheres, produzindo estratégias para sobreviver aos perigos e manter suas famílias e moradias.

Entre outras históricas e longevas formas de violência que nos últimos anos parecem ter se agudizado no país, está aquela no meio rural, associada fortemente à repressão policial aos movimentos sociais e aos conflitos de disputas territoriais. Alguns destes movimentos sociais, associados ao processo de democratização no final da ditadura, derivam da forte presença da Teologia da Libertação e suas Comunidades e Comissões Pastorais. O artigo de Igor Rolemberg, "Ritual, emoções e engajamento militante: a produção em ato da mística na romaria dos mártires da floresta em Nova Ipixuna/PA", retoma a mística na romaria que rememora a morte violenta de duas lideranças assassinadas em assentamentos agroextrativistas, na região de Marabá e Xinguara, sudeste do Pará. Nesta análise, nota-se como a romaria reelabora e reconstrói a memória de lutas, numa recorrente produção e circulação de sentimentos. Mais uma vez, nesta edição, pode-se notar como a memória assume um papel ativo na produção e circulação de sentidos e de ações.

O conflito de terras reaparece na Amazônia equatoriana, desta vez envolvendo a lógica do Estado e dos projetos econômicos extrativistas e o modo de vida de subgrupos do povo Waorani, cuja territorialidade é marcada pela dispersão e pelo deslocamento, mas também pela memória dos lugares e dos antepassados. Em "Fronteras irreales, abuelos y territorios comunes: interdependencia y interrelación de waorani y grupos familiares en aislamiento en el Yasuní", Roberto Narvaez tece uma crítica às políticas públicas e ao governo neoliberal do Equador. Vítimas da expansão do petróleo, das madeireiras, e mais recentemente de garimpeiros, os Waorani - tanto os de recente contato como aqueles que procuram se manter em isolamento - são testemunhas de um quadro cada vez mais crítico de desrespeito aos direitos indígenas e de destruição do ambiente que habitam. O cenário descrito no Yasuní, no Equador, não destoa infelizmente da realidade da Amazônia brasileira, na qual as invasões das terras indígenas - especialmente por garimpeiros - se multiplicam, espelhando o descaso de um governo francamente antiindígena. Veja-se, por 
exemplo, os conflitos e a violência que irromperam no último mês na Terra Indígena Yanomami e nas Terras Indígenas Munduruku e Sai Cinza.

Tem sido missão da antropologia não apenas revelar desigualdades estruturais e formas de violência e agressões a modos de vida tradicionais, mas também refletir sobre políticas públicas, bem como sobre enfrentamentos e estratégias de ação de grupos minoritários e precarizados. Tratando de outra parte do mundo que muito sofreu com a violência do Estado e retomando questões de gênero e família, o artigo "Granting the Future? The Temporality of Cash Transfers in the South African Countryside", de Bernard Dubbeld, reflete sobre as moralidades, os arranjos familiares e as projeções de futuro no contexto da política de transferência de renda na África do Sul, após o fim do apartheid, na província de KwaZulu-Natal. Embora essa política tenha acarretado importantes transformações no que diz respeito à estrutura de poder e às relações de gênero e familiares, Dubbeld busca compreender por que o trabalho assalariado, ainda que precarizado, permanece um valor e um objetivo para essas famílias, que atualmente sobrevivem com as políticas de transferência de renda.

Retomando o papel da memória na constituição de formas de ação, o artigo de Marcelo Moura Mello, "Espíritos, História e Colonialismo na Guiana", explora como hindus, descendentes dos trabalhadores de origem indiana que vieram trabalhar por contrato (indentures) nas plantações de cana-de-açúcar no período do domínio britânico na Guiana, lidam com a história violenta da colonização da região. Para acalmar espíritos de antigos colonizadores holandeses (vistos como "donos da terra"), vencidos na guerra entre as metrópoles, eles aprimoraram rituais e oferendas, retomando práticas hindus, como o culto a Kali.

Incorporando a discussão sobre entidades, rituais e processos religiosos em estreita conexão com campos de disputa de poder e desigualdades sociais, marcados por processos de racialização, o artigo de Moura dialoga com o trabalho de Emerson Giumbelli e Leonardo Oliveira de Almeida. "O Enigma da quimbanda: formas de existência e de exposição de uma modalidade religiosa afro-brasileira no Rio Grande do Sul" retoma a particularidade da quimbanda no Rio Grande do Sul, por ter assumido uma visibilidade distinta da que prevalece no resto do país, remetendo a uma categoria de acusação. Reportando-se a etnografias recentes em terreiros de quimbanda e levando em conta a produção da materialidade nas formas religiosas, o artigo descortina as condições de possibilidade dessa prática no campo religioso gaúcho. Destaca como as entidades cultuadas pela quimbanda se constituíram a partir de deslocamentos da umbanda e do 
batuque: exus e pombagiras deixariam a posição de marginalidade para "evoluírem" rumo a um patamar de nobreza.

Da política dos espíritos podemos então passar para a política dos animais. $\mathrm{O}$ artigo de Ana Paula Perrota Franco traz uma aguda reflexão sobre como se articula a noção de direitos dos animais para os militantes e defensores desta causa, em diálogo com reflexões filosóficas sobre as noções de humano e animal, e na busca do rompimento desta fronteira. Tendo em vista a expansão crescente da noção de direitos humanos na direção de outros seres viventes, a autora destaca a lógica e as contradições que orientam uma busca por igualdade entre humanos e animais no plano moral e jurídico.

Lucas da Costa Maciel reflete sobre a contribuição do pensamento de Gayatri Spivak para os estudos pós-coloniais e, mais especificamente, para a antropologia. Em "Spivak, pós-colonialidade e Antropologia: pensar o pensamento e o colonialismo-embranco dos nossos conceitos" temos uma arqueologia do conhecido ensaio da autora, atentando para a suplementação pelo método da desconstrução derridiana do conceito de subalternidade, noção gramsciana retomada pelos acadêmicos indianos na discussão da colonialidade. O artigo busca, por fim, conectar a proposta de Spivak ao recente "ontologismo antropológico", que ressalta o laço entre ontologia, epistemologia e política.

Três artigos, por fim, destacam-se pelo foco na dimensão sensível da vida social, um deles refletindo mais especificamente sobre o fazer etnográfico, os demais concentrando-se sobre as potencialidades da música e dos instrumentos musicais.

Marina Ramos Neves Castro oferece um balanço bibliográfico crítico sobre as diferenças entre a antropologia dos sentidos e etnografia sensorial. Para a segunda, os sentidos deixariam de ser meramente "objetos" para guiar a pesquisa. Isto é, a etnografia teria de se deixar levar pela sensorialidade, habitando lugares para além da linguagem verbal. Isso implicaria uma reflexão mais situada e interativa com interlocutores da pesquisa.

De certo modo, os dois artigos sobre música aqui reunidos situam-se no meio fio entre essas duas antropologias, ainda que os autores não façam referência a elas em termos de campos de conhecimento.

O artigo de Rafael Menezes Bastos, "Sobre as flautas sagradas xinguanas e a antropologização do mundo", reflete sobre esses instrumentos de sopro de suma importância para a vida ritual em diferentes regiões da Amazônia indígena, instrumentos interditos à visão das mulheres e associados aos espíritos geradores de arte e de doenças. Menezes Bastos detém-se no seu importante trabalho de antropologia da música com o 
de Niemeyer Cesarino, Laura Moutinho, Júlio Assis Simões |

Afinando reflexões sobre um mundo em colapso

povo Kamayurá (tupi-guarani) do alto Xingu e, especialmente, no controverso caso de Leonardo Villas Boas com a esposa de um reputado chefe, que culmina na expulsão da mulher, incitada a ver o que Ihe era proibido: as flautas. Segundo Menezes Bastos, as flautas ditas sagradas revelam-se, no alto Xingu e alhures, disparadoras de uma "biopolítica da sensorialidade". O autor reúne de maneira engenhosa autores como Foucault, Clastres e Latour para evidenciar a centralidade desses aerofones na cosmopolítica ameríndia, em que humanos e espíritos, homens e mulheres permanecem em permanente disputa e interação.

No artigo "Em busca do limiar sonoro: gestos, sons e riscos - afinação nas folias", Wagner Diniz Chaves oferece uma preciosa análise das folias de reis no Norte de Minas Gerais, nas quais os instrumentos de corda são centrais. Como o trio de flautas sagradas alto-xinguano, eles também carregam perigo, no caso, o risco envolvido no processo de sua afinação. Na Taboquinha, município de São Francisco, a afinação dos instrumentos de corda durante as folias seria um ato perigoso, envolvendo diferentes planos - sensorial, ritual, temporal e cosmológico. Como no caso alto-xinguano, uma execução errada pode acarretar infortúnio ao executor ou a irrupção mesma do caos. Mais uma vez, a música e sua cosmopolítica, busca perpétua da justa afinação em um mundo invadido por incongruências.

Heloisa Buarque de Almeida é professora doutora no Departamento de Antropologia e no PPGAS-USP, e membro do NUMAS - Núcleo de Estudos dos Marcadores Sociais da Diferença. Foi Visiting Fellow na London School of Economics com bolsa FAPESP, é e membro do Conselho Científico da Associação Brasileira de Antropologia. É bolsista de produtividade do CNPq, e tem apoio da FAPESP.

Renato Sztutman é professor do Departamento de Antropologia e do Programa de PósGraduação em Antropologia Social (PPGAS) da Universidade de São Paulo. É bolsista produtividade do CNPq. Autor do livro O profeta e o principal: a ação política ameríndia e seus personagens (Edusp/ Fapesp,2012).

Pedro de Niemeyer Cesarino é professor doutor do Departamento de Antropologia da FFLCH/USP e editor-chefe da Revista de Antropologia. Pulicou Oniska - poética do xamanismo na Amazônia (Ed. Perspectiva/FAPESP, 2011), Quando a Terra deixou de falar - cantos da mitologia marubo (Ed. 34, 2013), entre outros livros e artigos. 
Laura Moutinho é professora Associada (Livre-Docente) do Departamento de Antropologia e do PPGAS ambos da USP. Pesquisadora do NUMAS/USP. Coordena a Comissão Projeto Editorial da ABA. Publicou o livro Razão, Cor e Desejo: uma análise dos relacionamentos afetivo-sexuais inter-raciais no Brasil e África do Sul, Editora Unesp: São Paulo, 2004, graças ao prêmio EDUSC\ANPOCS para melhor tese de doutoradoledição 2003. É bolsista produtividade do CNPq e tem apoio da FAPESP.

Júlio Assis Simões é professor do Departamento de Antropologia e do Programa de PósGraduação em Antropologia Social da USP. É pesquisador líder do NUMAS - Núcleo de Estudos dos Marcadores Sociais da Diferença e bolsista de produtividade do CNPq. 


\section{REFERÊNCIAS BIBLIOGRÁFICAS}

BASTOS, Rafael José de Menezes.

2021. "Sobre as flautas sagradas xinguanas e a antropologização do mundo". Revista de Antropologia, 64(2): e186653.

http://dx.doi.org/10.11606/1678-

9857.ra.2021.186653

BIRMAN, Patrícia; PIEROBON,

Camila. 2021. "Viver sem guerra?

Poderes locais e enfrentamentos de gênero no cotidiano popular". Revista de Antropologia, 64(2): e186647. http://dx.doi.org/10.11606/16789857.ra.2021.186647

CASTRO, Marina Ramos Neves de. 2021. "A antropologia dos sentidos e a etnografia sensorial: dissonâncias, assonâncias e ressonâncias". Revista de Antropologia, 64(2): e186657. http://dx.doi.org/10.11606/16789857.ra.2021.186657

CHAVES, Wagner Diniz. 2021. "Em busca do limiar sonoro: gestos, sons e riscos na afinação das folias". Revista de Antropologia, 64(2): e186654. http://dx.doi.org/10.11606/16789857.ra.2021.186654

DUBBELD, Bernard. 2021. "Granting the Future? The Temporality of Cash Transfers in the South African Countryside". Revista de Antropologia, 64(2): e186648.
GIUMBELLI, Emerson Alessandro; ALMEIDA, Leonardo Oliveira de. 2021. "O enigma da quimbanda: formas de existência e de exposição de uma modalidade religiosa afro-brasileira no Rio Grande do Sul". Revista de Antropologia, 64(2): e186652. http://dx.doi.org/10.11606/16789857.ra.2021.186652

MACIEL, Lucas da Costa. 2021. "Spivak, pós-colonialismo e antropologia: pensar o pensamento e o colonialismo-em-branco dos nossos conceitos". Revista de Antropologia, 64(2): e186659. http://dx.doi.org/ 10.11606/1678-9857.ra.2021.186659

MELLO, Marcelo Moura. 2021. "Espíritos, história e colonialismo na Guiana". Revista de Antropologia, 64(2): e186650.

http://dx.doi.org/10.11606/16789857.ra.2021.186650

NARVAEZ, Roberto. 2021. "Fronteras irreales, abuelos y territorios comunes: interdependencia e interrelación de waorani y grupos familiares en aislamiento en el Yasuní". Revista de Antropologia, 64(2): e186655

ROLEMBERG, Igor. 2021. "Ritual, emoções e engajamento militante: a produção em ato da mística na romaria dos mártires da floresta em Nova

Rev. antropol. (São Paulo, Online) | v. 64 n. 2: e187398 | USP, 2021 
editoriAl | Heloisa Buarque de Almeida, Renato Sztutman, Pedro de Niemeyer Cesarino, Laura Moutinho, Júlio Assis Simões |

Afinando reflexões sobre um mundo em colapso

http://dx.doi.org/10.11606/1678-

Ipixuna/PA". Revista de Antropologia,

9857.ra.2021.186648 64(2): e186656.

http://dx.doi.org/10.11606/1678-

FRANCO, Ana Paula Perrota. 2021.

9857.ra.2021.186656

"Animais e direitos: as fronteiras do

humanismo e do sujeito em questão".

Revista de Antropologia, 64(2):

e186658.

http://dx.doi.org/10.11606/1678-

9857.ra.2021.186658

Rev. antropol. (São Paulo, Online) | v. 64 n. 2: e187398 | USP, 2021 